\title{
Afghan people risk their lives to obtain health care: MSF
}

$\mathrm{D}$

espite years of aid and investment, medical care in Afghanistan remains severely limited and is "often non-existent, prohibitively expensive or inaccessible" where needed most, states Médecins Sans Frontières (MSF) in a new report.

The humanitarian organization warns that the situation will worsen in coming months, as the bulk of foreign troops withdraw from Afghanistan, aid dollars dwindle and violence continues to intensify.

Meanwhile, official accounts frequently mask the extent of barriers to affordable, quality care, MSF charges in its Feb. 25 report, Between rhetoric and reality: The ongoing struggle to access healthcare in Afghanistan.

National statistics boast that some $57 \%$ of Afghans now live within walking distance of a public health facility, where free care is delivered through contracts with non-state providers, compared to just $9 \%$ in 2001.

But many patients avoid their closest clinic because of recurring problems with staffing, drug availability and basic quality of care, says Dr. Catherine Van Overloop, medical coordinator for MSF in Afghanistan. "It's not the big success story that has been put forward."

Reliable data on access to health care are hard to come by, but MSF interviews with more than 800 people in hospitals across Afghanistan indicated that many were often taking lifethreatening risks to get malnourished babies, pregnant women and injured family members to medical aid.

"One in five patients told us they had lost a family member or close friend in the last year because of lack of access to health care," says Van Overloop. For those who reached MSF hospitals, $40 \%$ said they experienced fighting, landmines, checkpoints or harassment on their journey.

"They are too scared to travel during the night," says Van Overloop. "We hear a lot of stories of families keeping deathwatches over their sick and wounded in the hope they'll survive until morning to make the trip to the hospital."

The threat of violence, distance to adequate health facilities and the prohibi-

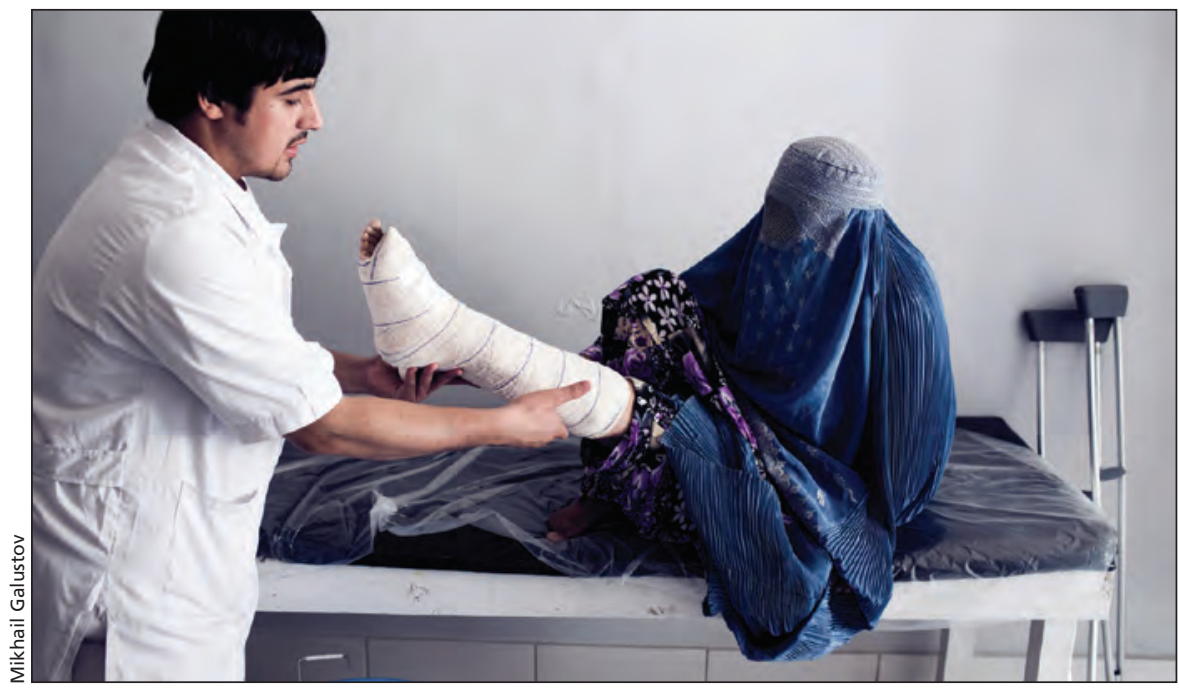

An MSF health care worker treats a female patient at the Kunduz Trauma Center in Kunduz, Afghanistan.

tive cost of travel are such that many people delay seeking care for as long as possible. In Helmand province, nearly half (46\%) of the patients MSF interviewed had waited more than a week before making the trip to a hospital. Over one in five $(22 \%)$ had waited more than two weeks. And in both Helmand and Kabul, $60 \%$ of people with a malnourished child waited more than a month to seek care.

Those who do make it to a local government-run clinic often find that it is "closed, defunct or provides inadequate services," according to the report. Four in five (79\%) people said they had bypassed those clinics altogether during a previous illness in the preceding three months.

Although Afghanistan's public health system promises free care, in practice, patients said this is not always the case. One in three (66\%) described their families as poor or extremely poor, living on around US\$1 a day. Yet people reported paying an average US $\$ 40$ for health care during a recent illness in their household, with one in four spending more than US $\$ 114$.

Distrust of the public system is often coupled with misplaced trust in the "enormously powerful and unregulated" private system, where "overprescribing, misdiagnosing and even malpractice" go unchecked, according to MSF.

Georgann MacDonald, a Canadian nurse practitioner who volunteered for nine months with MSF in Helmand province last year, recalls pregnant patients showing up with "shopping bags full of medicines that their doctors had prescribed and sold to them."

"We never knew what medications patients were taking," she says. "There were no controls."

MSF largely attributes gaps in care to the fact that the bulk of investment in health has come from foreign powers with military interests in Afghanistan, with a disproportionate share directed to areas where troops were present, regardless of local needs.

Macdonald worries what this will mean for the humanitarians left behind after international troops withdraw by the end of 2014. "Why would the Afghan people trust them when armies present themselves as humanitarians?"

According to MSF, access for humanitarians to remote and insecure areas has been shrinking and already "many aid providers are bunkered inside main cities and towns."

"We've left Afghanistan in the past," says Macdonald, citing MSF's withdrawal from the region in 2004 after the murder of five staff. Reflecting on the recent bombing of a favourite restaurant in Kabul, she adds: "That easily could have been me, and then would MSF leave again?" - Lauren Vogel, CMAJ

CMAJ 2014. DOI:10.1503/cmaj.109-4751 